\title{
Papers
}

\section{Adverse socioeconomic conditions in childhood and cause specific adult mortality: prospective observational study}

\author{
George Davey Smith, Carole Hart, David Blane, David Hole
}

\begin{abstract}
Objective: To investigate the association between social circumstances in childhood and mortality from various causes of death in adulthood.

Design: Prospective observational study.

Setting: 27 workplaces in the west of Scotland.

Subjects: 5645 men aged 35-64 years at the time of examination.

Main outcome measures: Death from various causes. Results: Men whose fathers had manual occupations when they were children were more likely as adults to have manual jobs and be living in deprived areas. Gradients in mortality from coronary heart disease, stroke, lung cancer, stomach cancer, and respiratory disease were seen (all $\mathrm{P}<0.05$ ), generally increasing from men whose fathers had professional and managerial occupations (social class I and II) to those whose fathers had semiskilled and unskilled manual occupations (social class IV and V). Relative rates of mortality adjusted for age for men with fathers in manual versus non-manual occupations were 1.52 (95\% confidence interval 1.24 to 1.87) for coronary heart disease, 1.83 (1.13 to 2.94) for stroke, 1.65 (1.12 to 2.43) for lung cancer, 2.06 (0.93 to 4.57) for stomach cancer, and 2.01 (1.17 to 3.48) for respiratory disease. Mortality from other cancers and accidental and violent death showed no association with fathers' social class. Adjustment for adult socioeconomic circumstances and risk factors did not alter results for mortality from stroke and stomach cancer, attenuated the increased risk of coronary heart disease and respiratory disease, and essentially eliminated the association with lung cancer.
\end{abstract}

Conclusions: Adverse socioeconomic circumstances in childhood have a specific influence on mortality from stroke and stomach cancer in adulthood, which is not due to the continuity of social disadvantage throughout life. Deprivation in childhood influences risk of mortality from coronary heart disease and respiratory disease in adulthood, although an additive influence of adulthood circumstances is seen in these cases. Mortality from lung cancer, other cancer, and accidents and violence is predominantly influenced by risk factors that are related to social circumstances in adulthood.

\section{Introduction}

The long term influence of poor social circumstances in early life on risk of disease in adulthood has been recognised for many years. ${ }^{1}$ Several studies relating socioeconomic position in childhood to adulthood morbidity and mortality have appeared,,$^{2-4}$ and influences on mortality from all causes and from cardiovascular disease have been observed. ${ }^{45} \mathrm{~A}$ particular problem with such studies is that socioeconomic circumstances in childhood and adulthood are linked, ${ }^{6}$ and the specific effects of socioeconomic conditions in early life, as opposed to the continuing effects of deprivation throughout life, have been difficult to isolate.

If the specific influence of socioeconomic environment in early life is to be investigated studies with data on circumstances in early and later life are required. Associations can be investigated by examining different causes of morbidity and mortality as the processes initiated by socioeconomic deprivation in early life will have specific influences on particular diseases. Similarly, the expectation is that some causes of morbidity and mortality would be mainly influenced by circumstances in adulthood. We have investigated the association between socioeconomic position in early life and cause specific mortality in the collaboration study, a large cohort of men in the west of Scotland, to identify the specific influences of socioeconomic environment in early life on later health.

\section{Methods}

This analysis is based on a cohort of 5766 men aged 35-64 at the time of examination who were recruited from workplaces in the west of Scotland between 1970 and 1973. Full details regarding the present study population (the collaborative study) and the methods of data collection that were used have been presented previously. ${ }^{78}$

The information collected at baseline examination included:

- Sociodemographic data: age, father's occupation, subject's occupation at the time of screening (coded to social class), and whether he was a regular car driver

- Measures of health status: angina from the Rose questionnaire and respiratory symptoms from the Medical Research Council questionnaire

- Health related behaviours: detailed smoking history
Department of
Social Medicine,
University of
Bristol, Canynge
Hall, Bristol
BS8 2PR
George Davey 
Table 1 Population characteristics according to fathers' social class. Values are age adjusted means or proportions unless stated otherwise

\begin{tabular}{|c|c|c|c|c|c|}
\hline \multirow[b]{2}{*}{ Characteristic } & \multicolumn{4}{|c|}{ Fathers' social class } & \multirow[b]{2}{*}{$\begin{array}{l}P \text { value } \\
\text { for trend }\end{array}$} \\
\hline & $\begin{array}{l}I \text { and II } \\
(n=787)\end{array}$ & $\underset{\substack{\text { IIIN } \\
(n=582)}}{\ln }$ & $\underset{(n=2457)}{\text { IIIM }}$ & $\begin{array}{l}\text { IV and V } \\
(n=1819)\end{array}$ & \\
\hline Age (years) ${ }^{\star}$ & 48.1 & 47.8 & 48.5 & 48.1 & 0.57 \\
\hline Current social class I and II (\%) & 72.2 & 54.4 & 27.6 & 15.0 & 0.0001 \\
\hline Regular drivers (\%) & 71.0 & 57.5 & 50.1 & 44.0 & 0.0001 \\
\hline Deprivation category 5-7 (\%) & 24.3 & 29.1 & 53.0 & 58.5 & 0.0001 \\
\hline Angina $(\%)$ & 4.0 & 5.2 & 6.6 & 6.9 & 0.002 \\
\hline Ischaemia on electrocardiogram (\%) & 6.3 & 4.5 & 5.8 & 6.1 & 0.66 \\
\hline Bronchitis (\%) & 0.8 & 1.4 & 2.1 & 3.2 & 0.0001 \\
\hline Height $(\mathrm{cm})$ & 176.0 & 174.4 & 172.5 & 171.4 & 0.0001 \\
\hline $\mathrm{FEV}_{1}$ score $(\%)$ & 99.2 & 97.1 & 93.8 & 91.8 & 0.0001 \\
\hline Cholesterol (mmol/l) & 6.18 & 6.05 & 5.85 & 5.75 & 0.0001 \\
\hline Body mass index $\left(\mathrm{kg} / \mathrm{m}^{2}\right)$ & 25.0 & 24.7 & 25.2 & 25.4 & 0.0001 \\
\hline Current cigarette smoker (\%) & 48.4 & 47.8 & 56.5 & 58.9 & 0.0001 \\
\hline Diastolic blood pressure $(\mathrm{mm} \mathrm{Hg})$ & 82.5 & 83.1 & 84.1 & 84.3 & 0.0001 \\
\hline
\end{tabular}

*Not age adjusted. manual). For the adjustments the subjects' own social class was treated at six levels.

Mortality over a 21 year follow up period was ascertained by flagging at the NHS central registry in Edinburgh, which also provided death certificates coded according to ICD-9 (international classification of diseases, 9 th revision).

Mortality rates were standardised for age by the direct method by using the total study population as the standard. Tests for trends of age adjusted rates were obtained by proportional hazards regression with the PROC PHREG program in the SAS system, with age and social class (coded as a continuous variable) as covariates. Continuous variables were standardised for age with the PROC GLM program, with tests for trends in age adjusted means obtained with the PROC REG program. Categorical variables were age standardised by the direct method and tests for trends performed with the PROC LOGIST program. Proportional hazards coefficients and their standard errors were calculated with adjustment for age and other risk factors by including terms for these in the proportional hazards models. Exponential hazards coefficients were taken as indicators of relative rates of death.

\section{Results}

Data on demographic factors, morbidity, and cardiovascular risk factors according to fathers' occupational social class are presented in table 1 . Men with fathers in non-manual social classes (I and II) were more likely to be in non-manual social classes themselves, to live in less deprived areas, to be taller, to be less likely to smoke, to report less angina or bronchitis, and to have lower diastolic blood pressure, higher $\mathrm{FEV}_{1}$ scores, higher serum cholesterol concentrations, and lower body mass indices. Men with fathers in manual social

Table 2 Relative rates of mortality (95\% confidence intervals) adjusted for age and socioeconomic position in adulthood, with number of deaths

\begin{tabular}{|c|c|c|c|c|c|}
\hline \multirow[b]{2}{*}{ Cause of death and adjustment } & \multicolumn{4}{|c|}{ Fathers' social class } & \multirow{2}{*}{$\begin{array}{l}\mathrm{P} \text { value } \\
\text { for trend }\end{array}$} \\
\hline & I and II & IIIN & IIIM & IV and V & \\
\hline \multicolumn{6}{|l|}{ All causes $(n=1602)$} \\
\hline Age & 1 & $1.12(0.89$ to 1.40$)$ & $1.48(1.25$ to 1.75$)$ & 1.54 (1.29 to 1.82$)$ & 0.0001 \\
\hline Age and adult social class & 1 & 1.06 (0.84 to 1.33$)$ & 1.28 (1.08 to 1.53$)$ & 1.26 (1.05 to 1.52$)$ & 0.011 \\
\hline \multicolumn{6}{|l|}{ Coronary heart disease $(n=618)$} \\
\hline Age & 1 & 0.96 (0.65 to 1.40$)$ & 1.47 (1.13 to 1.92$)$ & 1.53 (1.16 to 2.01$)$ & 0.0003 \\
\hline Age and adult social class & 1 & 0.91 (0.62 to 1.33$)$ & $1.28(0.96$ to 1.69$)$ & $1.26(0.93$ to 1.70$)$ & 0.064 \\
\hline \multicolumn{6}{|l|}{ Stroke $(n=130)$} \\
\hline Age & 1 & 0.79 (0.31 to 1.97$)$ & 1.64 (0.91 to 2.98) & $1.70(0.92$ to 3.15$)$ & 0.031 \\
\hline Age and adult social class & 1 & 0.78 (0.31 to 1.96$)$ & 1.62 (0.87 to 3.02$)$ & $1.66(0.86$ to 3.24$)$ & 0.061 \\
\hline \multicolumn{6}{|l|}{ Lung cancer ( $\mathrm{n=185)}$} \\
\hline Age & 1 & 1.49 (0.74 to 3.02$)$ & 2.13 (1.24 to 3.68$)$ & $1.80(1.02$ to 3.17$)$ & 0.045 \\
\hline Age and adult social class & 1 & 1.35 (0.67 to 2.74$)$ & $1.62(0.92$ to 2.85$)$ & 1.24 (0.68 to 2.27) & 0.75 \\
\hline \multicolumn{6}{|l|}{ Stomach cancer $(\mathrm{n}=50)$} \\
\hline Age & 1 & $1.06(0.24$ to 4.74$)$ & 1.51 (0.51 to 4.46$)$ & 2.95 (1.03 to 8.47$)$ & 0.011 \\
\hline Age and adult social class & 1 & 1.06 (0.24 to 4.77$)$ & 1.51 (0.49 to 4.65$)$ & 2.95 (0.95 to 9.16$)$ & 0.017 \\
\hline \multicolumn{6}{|l|}{ Other cancers $(\mathrm{n}=272)$} \\
\hline Age & 1 & 1.49 (0.93 to 2.38$)$ & 1.27 (0.87 to 1.85$)$ & 1.05 (0.70 to 1.57$)$ & 0.78 \\
\hline Age and adult social class & 1 & 1.45 (0.91 to 2.33 ) & $1.18(0.79$ to 1.76$)$ & 0.95 (0.61 to 1.48$)$ & 0.46 \\
\hline \multicolumn{6}{|l|}{ Respiratory disease $(\mathrm{n}=105)$} \\
\hline Age & 1 & 1.65 (0.60 to 4.55$)$ & 2.41 (1.09 to 5.31$)$ & 2.75 (1.23 to 6.14$)$ & 0.008 \\
\hline Age and adult social class & 1 & 1.52 (0.55 to 4.22$)$ & 1.97 (0.87 to 4.47$)$ & $2.10(0.90$ to 4.90$)$ & 0.092 \\
\hline \multicolumn{6}{|l|}{ Accidents and violence $(n=51)$} \\
\hline Age & 1 & 0.52 (0.14 to 1.95$)$ & $0.84(0.37$ to 1.90$)$ & $1.15(0.51$ to 2.62$)$ & 0.47 \\
\hline Age and adult social class & 1 & $0.43(0.11$ to 1.64$)$ & $0.50(0.21$ to 1.19$)$ & 0.58 (0.23 to 1.42$)$ & 0.42 \\
\hline
\end{tabular}


classes (IIIM, IV, and V) were less likely to be regular car drivers. Being a regular car driver was taken to be a marker for ownership of a car, which has been used in various studies as an indicator of available income.

Over the 21 years of follow up 1602 cohort members died. Relative rates of mortality adjusted for age for all causes, coronary heart disease, stroke, lung cancer, stomach cancer, other cancer, respiratory disease, and accidents and violence are presented in table 2. The risks of all cause mortality and the specific causes examined, with the exception of other cancer and accidents and violence, were higher among men whose fathers were in manual compared with non-manual occupations with significant tests for trend across the fathers' social class groups.

Relative mortalities adjusted for age and social class in adulthood are also presented in table 2. The graded association between fathers' social class and mortality from lung cancer was essentially abolished by adjustment for subjects' social class in adulthood; for mortality from coronary heart disease and respiratory disease the association was attenuated but remained evident, while for mortality from stroke and stomach cancer there was essentially no attenuation of the association after adjustment for adult social class.

Table 3 presents relative mortalities adjusted for age, adult sociodemographic indicators, and other risk factors. The sociodemographic indicators adjusted for were adult social class, deprivation category based on area of residence, and car use. For mortality from all causes, coronary heart disease, and stroke the risk factors adjusted for were smoking (number of cigarettes smoked, with an additional adjustment for being a former smoker), diastolic blood pressure, serum cholesterol concentration, body mass index, and adjusted $\mathrm{FEV}_{1}$ score. These represent the available data on risk factors for cardiovascular disease, some of which are also important risk factors for other causes of death. For mortality from cancer and respiratory disease the risk factors adjusted for were smoking, body mass index, and $\mathrm{FEV}_{1}$ score as these factors have been identified as important predictors of death from these causes. After adjustment for the risk factors together with the adult sociodemographic indicators the increased risk of mortality from stroke and stomach cancer, and to a lesser degree from coronary heart disease and respiratory disease, remained evident for men whose fathers were in manual occupations.

While adjustment for adult sociodemographic factors resulted in a non-significant trend across the four social class groupings for mortality from coronary heart disease the increased risk among the men with fathers in manual occupations remained significant. For mortality from stroke the equivalent increased risk was more striking and remained after adjustment for adulthood social indicators.

To examine the hypothesis that deprivation in early life followed by later affluence is associated with an increased risk of mortality from cardiovascular disease we examined mortality from coronary heart disease and stroke according to social class in childhood and adulthood (table 4). The specific influence of socioeconomic position in childhood on risk of stroke was confirmed in these analyses. There was no strong effect of upward social mobility on the risk of mortality from either coronary heart disease or stroke, with none
Table 3 Relative rates of mortality for men with fathers of manual social class adjusted for socioeconomic indicators and other risk factors, with non-manual fathers' social class as baseline. $P$ values for trend given for test across the four social class groupings used in tables 1 and 2

\begin{tabular}{|c|c|c|}
\hline Cause of death and adjustment & Manual social class & $\begin{array}{l}\text { P value } \\
\text { for trend }\end{array}$ \\
\hline \multicolumn{3}{|l|}{ All causes } \\
\hline Age & $1.44^{\star \star *}(1.27$ to 1.63$)$ & 0.0001 \\
\hline Age, adult social class, deprivation category, car & $1.22^{* *}(1.06$ to 1.39$)$ & 0.024 \\
\hline Age, adult social class, deprivation category, car, risk factors $\dagger$ & $1.19^{* *}(1.04$ to 1.37$)$ & 0.042 \\
\hline \multicolumn{3}{|l|}{ Coronary heart disease } \\
\hline Age & $1.52^{\star \star \star}(1.24$ to 1.87$)$ & 0.0003 \\
\hline Age, adult social class, deprivation category, car & $1.28^{*}(1.03$ to 1.61$)$ & 0.11 \\
\hline Age, adult social class, deprivation category, car, risk factors $\dagger$ & $1.26^{*}(1.01$ to 1.58$)$ & 0.12 \\
\hline \multicolumn{3}{|l|}{ Stroke } \\
\hline Age & $1.83^{* *}(1.13$ to 2.94$)$ & 0.031 \\
\hline Age, adult social class, deprivation category, car & $1.87^{\star}(1.12$ to 3.12$)$ & 0.049 \\
\hline Age, adult social class, deprivation category, car, risk factors $\dagger$ & $1.74^{*}(1.05$ to 2.90$)$ & 0.079 \\
\hline \multicolumn{3}{|l|}{ Lung cancer } \\
\hline Age & $1.65^{* *}(1.12$ to 2.43$)$ & 0.045 \\
\hline Age, adult social class, deprivation category, car & $1.23(0.81$ to 1.87$)$ & 0.89 \\
\hline Age, adult social class, deprivation category, car, risk factorsł & $1.23(0.81$ to 1.88$)$ & 0.84 \\
\hline \multicolumn{3}{|l|}{ Stomach cancer } \\
\hline Age & $2.06(0.93$ to 4.57$)$ & 0.011 \\
\hline Age, adult social class, deprivation category, car & 2.03 (0.86 to 4.78$)$ & 0.014 \\
\hline Age, adult social class, deprivation category, car, risk factorsł & $2.03(0.86$ to 4.78$)$ & 0.012 \\
\hline \multicolumn{3}{|l|}{ Other cancer } \\
\hline Age & 0.98 (0.74 to 1.28$)$ & 0.78 \\
\hline Age, adult social class, deprivation category, car & 0.92 (0.68 to 1.25$)$ & 0.48 \\
\hline Age, adult social class, deprivation category, car, risk factorsł & 0.90 (0.67 to 1.23$)$ & 0.43 \\
\hline \multicolumn{3}{|l|}{ Respiratory disease } \\
\hline Age & $2.01^{* *}(1.17$ to 3.48$)$ & 0.008 \\
\hline Age, adult social class, deprivation category, car & $1.53(0.85$ to 2.75$)$ & 0.13 \\
\hline Age, adult social class, deprivation category, car, risk factorsł & 1.60 (0.88 to 2.90$)$ & 0.12 \\
\hline \multicolumn{3}{|l|}{ Accidents and violence } \\
\hline Age & $1.22(0.63$ to 2.38$)$ & 0.47 \\
\hline Age, adult social class, deprivation category, car & $0.68(0.33$ to 1.40$)$ & 0.34 \\
\hline
\end{tabular}

${ }^{*} \mathrm{P}<0.05$. ${ }^{* *} \mathrm{P}<0.01$. ${ }^{* \star *} \mathrm{P}<0.001$

†Adjusted for smoking, diastolic blood pressure, cholesterol, body mass index, and $\mathrm{FEV}_{1}$ score. $\ddagger$ Adjusted for smoking, body mass index, and $\mathrm{FEV}_{1}$ score.

Table 4 Mortality from coronary heart disease and stroke after 21 years' follow up according to social class at screening and fathers' social class. Values are relative rates adjusted for socioeconomic factors and risk factor profiles

\begin{tabular}{|c|c|c|c|c|}
\hline \multirow[b]{2}{*}{$\begin{array}{l}\text { Cause of death and } \\
\text { adjustment }\end{array}$} & \multicolumn{2}{|c|}{ Subject non-manual at screening } & \multicolumn{2}{|c|}{ Subject manual at screening } \\
\hline & $\begin{array}{l}\text { Non-manual } \\
\text { father }\end{array}$ & $\begin{array}{l}\text { Manual } \\
\text { father }\end{array}$ & $\begin{array}{l}\text { Non-manual } \\
\text { father }\end{array}$ & $\begin{array}{l}\text { Manual } \\
\text { father }\end{array}$ \\
\hline \multicolumn{5}{|c|}{ Coronary heart disease } \\
\hline Age & 1 & 1.51 (1.16 to 1.96$)$ & 1.68 (1.09 to 2.58$)$ & 1.82 (1.43 to 2.32$)$ \\
\hline Risk factors ${ }^{*}$ & 1 & $1.43(1.10$ to 1.86$)$ & 1.59 (1.02 to 2.48$)$ & 1.67 (1.27 to 2.18$)$ \\
\hline \multicolumn{5}{|l|}{ Stroke } \\
\hline Age & 1 & 1.84 (1.04 to 3.28$)$ & $1.12(0.37$ to 3.34$)$ & 1.88 (1.09 to 3.24$)$ \\
\hline Risk factors* & 1 & 1.74 (0.97 to 3.12$)$ & 0.94 (0.30 to 2.91) & 1.65 (0.90 to 3.03$)$ \\
\hline
\end{tabular}

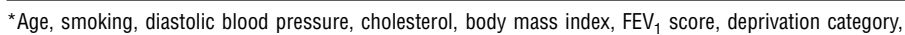
and car.

of the tests of interaction between fathers' and subjects' social class approaching significance.

\section{Discussion}

Studies of the association between socioeconomic circumstances and mortality have generally used assessments of socioeconomic position in adulthood. Attempts to explain the social distribution of all cause mortality and death from specific causes have similarly focused on exposures-such as health related behaviours, unfavourable occupational factors, or inadequate 
health care-acting during adult life. ${ }^{9}$ The potential of adverse childhood circumstances to produce socioeconomic differentials in health in adulthood has, however, been recognised by some observers for many years. ${ }^{1}$ Social position in adulthood is associated in similar fashion with many-but not all ${ }^{10}$-causes of death. Examining the association between childhood socioeconomic circumstances and cause specific mortality in adulthood, with adjustment for social conditions in adulthood, is one approach to determining which associations may reflect the specific influence of factors acting in early life. We have shown that stroke and stomach cancer, and to a lesser extent coronary heart disease and respiratory disease, seem to be influenced by childhood circumstances in a way that other causes of death, which are equally or more strongly socially patterned in adulthood-for example, lung cancer and accidents and violence-are not.

\section{Stroke and stomach cancer}

Areas with high maternal and neonatal mortality earlier this century have high current rates of death from stroke, ${ }^{11}$ which could indicate that unfavourable environments in early life influence later risk of stroke. The inverse association between birth weight and stroke observed in one study, ${ }^{12}$ together with extensive data demonstrating an inverse association between birth weight and later blood pressure, ${ }^{11}$ provide more direct evidence of the potential early life origins of stroke, although such individually based prospective studies remain susceptible to confounding by socioenvironmental factors in later life. Height in adulthood-in part an outcome of social environment in childhood-correlates negatively with mortality from stroke across the regions of England and Wales. ${ }^{13}$ Prospective studies also demonstrate an inverse association between height and risk of stroke. ${ }^{145}$ By showing associations after adjustment for various indicators of socioeconomic position in adulthood and risk factor profiles our data suggest that current socioeconomic differentials in risk of stroke reflect socioeconomic differentials in childhood experiences which occurred earlier this century.

Stroke and stomach cancer share several epidemiological features: sizeable, continuing, and unexplained declines in mortality over the century and similar geographical distributions, ${ }^{16}$ including unexpectedly low mortalities in the London area. ${ }^{16}$ Migrant studies suggest that the risk of stomach cancer is in part determined during early life, ${ }^{17}$ and current mortality correlates with markers of adverse socioeconomic circumstances earlier this century. ${ }^{18}$ Poor socioeconomic circumstances in childhood favour acquisition of Helicobacter pylori, ${ }^{19}$ and such infection may be an important cause of stomach cancer. ${ }^{20}$ Declining rates of $H$ pylori infection seem to have accompanied improving social conditions over the century $^{21}$ and thus may underlie the falling rates of death from stomach cancer. By allowing adjustment for socioeconomic position in adulthood our studythe first prospective investigation of this issue to our knowledge-supports the notion that an early life factor, possibly $H$ pylori infection, strongly influences the socioeconomic distribution of stomach cancer in adulthood. Infections acquired in childhood have also been implicated in the risk of stroke, and this could be responsible for the common epidemiological features of stroke and stomach cancer.

\section{Heart disease and respiratory disease}

Most $^{24522}$ but not all ${ }^{23}$ studies investigating the association between socioeconomic circumstances in childhood and risk of coronary heart disease have found an association similar to that found in the present study, which is not purely due to the adverse social class destinations of those born into poor circumstances. Forsdahl hypothesised that deprivation in early life followed by later affluence combined to produce a high risk of mortality from coronary heart disease. ${ }^{24}$ Our study, like several others that have examined this issue, ${ }^{2522}$ found no particular increase in risk of coronary heart disease among men born into families of manual social class who were themselves in non-manual jobs.

The influence of early life conditions on respiratory disease in adulthood has been studied for many years. ${ }^{3}$ Respiratory infections in childhood have been related to poor respiratory health in later life, and environmental influences on childhood respiratory functionsuch as damp housing, fumes from fuel burning, and air pollution-could influence the risk of later respiratory disease. ${ }^{25}$ In keeping with our findings that social circumstances in both childhood and adulthood influence mortality from respiratory disease, a cohort study from birth through to adulthood has shown that socially patterned exposures acting throughout life accumulate in their influence on adulthood respiratory health. ${ }^{26}$

\section{Other causes of death}

Deaths from lung cancer and accidents and violence are clearly influenced by exposures acting during adult life. Thus adjustment for adulthood socioeconomic position and, in the case of lung cancer, cigarette smoking greatly attenuated (in the case of lung cancer) or reversed (in the case of accidents and violence) the association between fathers' social class and mortality. While the (non-significant) residual relation between mortality from lung cancer and social class in childhood is only moderately weaker than that between childhood social class and mortality from coronary heart disease the important element is the change in relative risk after adjustment for confounders rather than magnitude of the residual effect itself. ${ }^{27}$

\section{Strengths and weaknesses of these methods}

Information on social circumstances in childhood was based on recall in adulthood. Recall of childhood socioeconomic position-on the basis of the occupational social class of the head of the household-has been shown to be reliable in a middle aged population in the United States. ${ }^{28}$ The question participants were asked in the present study related specifically to the main occupation of their father. In this cohort, for whom a change in socioeconomic circumstances during adult years would have been more likely than for their fathers, social mobility from labour market entry to middle age was low. ${ }^{7}$ As there is little change in social class position after young adulthood, the type of employment the fathers of the participants were in for most of their lives would generally be the same or similar to that they were in when their children were young. ${ }^{29}$ 
A particular strength of the present study is the ability to use multiple measures of adult socioeconomic position in the analyses. It is likely that in previous investigations the measures used-such as social class in adulthood-have been inadequate as many studies show that the better the classification of socioeconomic position the greater the mortality differentials observed. ${ }^{9}$ As there is likely to be more measurement error with respect to fathers' social class than subjects' social class we may be underestimating the influence of childhood social class in analyses that adjust for several well indexed markers of adulthood socioeconomic position. Our analyses therefore represent a powerful test of the hypothesis that there are specific influences of childhood social circumstances on adult mortality risk that are not merely due to the continuity of disadvantage throughout life.

A second strength of our study is the ability to adjust statistically for several risk factors for cardiovascular disease. This may represent overcontrol as childhood social circumstances may act through these risk factors to influence cardiovascular disease in adulthood. This applies particularly to body mass index, for which exposures acting in childhood seem to be responsible for the higher levels among men with fathers of manual social class. The same considerations, but to a lesser degree, apply to blood pressure and lung function. ${ }^{7}$

\section{Implications of our findings}

There are several implications of our findings. Firstly, attempts to explain the social distribution of adult health and risk of mortality must consider the influence of socioeconomic circumstances acting across the entire lifecourse. Studies with data covering only one point in time-whether this is early life or adulthood-face serious limitations in their ability to advance understanding. Secondly, the contribution of social circumstances in early life varies greatly between causes of death. This highlights the inadequacies of models that consider socioeconomic differentials in health to reflect a heightened general susceptibility to all diseases among those in adverse social circumstances. Thirdly, current changes in mortality rates for certain causes-including reductions in rates of stomach cancer and stroke-will reflect social changes that occurred several decades ago. Finally, the increasing child poverty seen in Britain and elsewhere over the past 20 years may well herald unfavourable future trends in adult health.

The work of Charles Gillis and Victor Hawthorne in establishing this cohort has provided us with the data required for this analysis.

Contributors: GDS, DH, and DB conceived and obtained funding for a project to analyse socioeconomic factors and health in the collaborative study cohort. $\mathrm{CH}$ was responsible for performing the statistical analyses, with the help of DH. DH was an original investigator on the Midspan series of studies, of which the collaborative study is a component. GDS prepared the first draft of this paper, and $\mathrm{CH}, \mathrm{DB}$, and $\mathrm{DH}$ contributed to the final submitted version. DH and GDS are guarantors for the study.

Funding: NHS Management Executive, Cardiovascular

Disease and Stroke Research and Development Initiative.

Conflict of interest: None.

1 Kuh D, Davey Smith G. When is mortality risk determined? Historical insights into a current debate. Soc Hist Med 1993;101-23.

2 Burr ML, Sweetnam PM. Family size and paternal unemployment in relation to myocardial infarction. J Epidemiol Community Health 1980;34:93-5.
- Adverse socioeconomic conditions in childhood are associated with mortality in later life

- Mortality from stroke and stomach cancer is particularly dependent on social circumstances in childhood

- Mortality from coronary heart disease and respiratory disease is dependent on social circumstances in both adulthood and childhood

- Mortality from accidents and violence and from lung cancer is mainly dependent on factors acting in adulthood

- The increases in child poverty seen in Britain and elsewhere over the past 20 years may herald unfavourable future trends in adult health

3 Elo IT, Preston SH. Effects of early-life conditions on adult mortality: a review. Popul Index 1992;58:186-212.

4 Vagero D, Leon D. Effect of social class in childhood and adulthood on adult mortality. Lancet 1994;343:1224-5.

5 Notkola V, Punsar S, Karvonen MJ, Haapakaski J. Socioeconomic conditions in childhood and mortality and morbidity caused by coronary heart disease in adulthood in rural Finland. Soc Sci Med 1985;21:517-23.

6 Ben-Shlomo Y, Davey Smith G, Deprivation in infancy or adult life: which is more important for mortality risk? Lancet 1991;337:530-4.

7 Blane D, Hart CL, Davey Smith G, Gillis CR, Hole DJ, Hawthorne VM. Association of cardiovascular disease risk factors with socioeconomic position during childhood and during adulthood. BMJ 1996;313:1434-8.

8 Davey Smith G, Hart C, Blane D, Gillis C, Hawthorne V. Lifetime socioeconomic position and mortality: prospective observational study. BMJ 1997;314:547-52.

9 Davey Smith G, Bartley M, Blane D. Explanations for socioeconomic differentials in mortality: evidence from Britain and elsewhere. Eur J Public Health 1994;4:131-44.

10 Davey Smith G, Neaton JD, Wentworth D, Stamler R, Stamler J. Socioeconomic differentials in mortality risk among men screened for the multiple risk factor intervention trial. I. Results for 300,685 white men. Am J Public Health 1996;86:486-96.

11 Barker DJP. Mothers, babies, and disease in later life. London: BMJ Publishing, 1994

12 Martyn CN, Barker DJP, Osmond C. Mothers' pelvic size, fetal growth, and death from stroke and coronary heart disease in men in the UK. Lancet 1996;348:1264-8.

13 Barker DJP, Osmond C, Golding J. Height and mortality in the countries of England and Wales. Ann Hum Biol 1990;17:1-6.

14 Leon D, Davey Smith G, Shipley M, Strachan D. Height and mortality in London: early life influences, socioeconomic confounding or shrinkage. J Epidemiol Community Health 1995;49:5-9.

15 Watt GCM, Hart CL, Hole DJ, Davey Smith G, Gillis CR, Hawthorne VM. Risk factors for cardiorespiratory and all cause mortality in men and women in urban Scotland: 15 year follow up. Scot Med J 1995;40:108-12.

16 Murray M. The geography of death in England and Wales. Ann Ass Am Geography 1962;52:130-49.

17 Coggon D, Osmond C, Barker DJP. Stomach cancer and migration within England and Wales. BrJ Cancer 1990;61:573-4.

18 Barker DJP, Coggon D, Osmond C Wickham C. Poor housing in childhood and high rates of stomach cancer in England and Wales Br J Cancer 1990;61:575-8.

19 Mendall MA, Goggin PM, Molineaux N, Levy J, Toosy T, Strachan D, et al. Childhood living conditions and Helicobacter pylori seropositivity in adult life. Lancet 1992:339:896-7.

20 Forman D, Newell DG, Fullerton F, Yarnell JWG, Stacey AR, Wald N, et al. Association between infection with Helicobacter pylori and risk of gastric cancer: evidence from a prospective investigation. BMJ 1991;302:1302-5.

21 Banatvala N, Mayo K, Megraud F, Jennings R, Deeks JJ, Feldman RA. The cohort effect and Helicobacter pylori. J Infect Dis 1993;168:219-21.

22 Wannamethee SG, Whincup PH, Shaper G, Walker M. Influence of fathers' social class on cardiovascular disease in middle-aged men. Lancet 1996;348:1259-63.

23 Haste H. Association between living conditions in childhood and myocardial infarction. BMJ 1990;300:289-98.

24 Forsdahl A. Are poor living conditions in childhood and adolescence an important risk factor for arteriosclerotic heart disease? Br J Prev Soc Med 1977;31:91-5.

$25 \mathrm{Wu}$ JM, Witorsch RJ, Witorsch P. Respiratory effects of socioeconomic status, gas stove usage, and other factors in children: an analytical survey of the epidemiological literature. In: Fechter LD, ed. Proceedings of the Fourth International Conference on the Combined Effects of Environmental FacFourth International Conference on the Combined Efect
tors. Baltimore: Johns Hopkins University, 1991.

26 Mann SL, Wadsworth MEJ, Colley JRT. Accumulation of factors influenc ing respiratory illness in members of a national birth cohort and their offspring. J Epidemiol Community Health 1992;46:256-92.

27 Phillips A, Davey Smith G. How independent are independent effects? Relative risk estimation when correlated exposures are measured imprecisely. J Clin Epidemiol 1991;44:1223-31.

28 Krieger N, Okamoto A, Selby JV. Twins recall of childhood social class and father's education: a validation study for public health research. AmJ Epidemiol (in press).

29 Payne G. Employment and opportunity. London: Macmillan, 1987

(Accepted 4 February 1998) 